\title{
Analysis of microseismic signals and temperature recordings for rock slope stability investigations in high mountain areas
}

\author{
C. Occhiena ${ }^{2}$, V. Coviello ${ }^{1,2}$, M. Arattano ${ }^{1}$, M. Chiarle ${ }^{1}$, U. Morra di Cella ${ }^{3}$, M. Pirulli ${ }^{2}$, P. Pogliotti ${ }^{3}$, and C. Scavia ${ }^{2}$ \\ ${ }^{1}$ Istituto di Ricerca per la Protezione Idrogeologica (IRPI), CNR, Torino, Italy \\ ${ }^{2}$ Department of Structural, Building and Geotechnical Engineering, Politecnico di Torino, Italy \\ ${ }^{3}$ Agenzia Regionale per la Protezione dell'Ambiente (ARPA), Regione Valle d'Aosta, Italy \\ Correspondence to: V. Coviello (velio.coviello@irpi.cnr.it)
}

Received: 15 February 2012 - Accepted: 17 May 2012 - Published: 20 July 2012

\begin{abstract}
The permafrost degradation is a probable cause for the increase of rock instabilities and rock falls observed in recent years in high mountain areas, particularly in the Alpine region. The phenomenon causes the thaw of the ice filling rock discontinuities; the water deriving from it subsequently freezes again inducing stresses in the rock mass that may lead, in the long term, to rock falls. To investigate these processes, a monitoring system composed by geophones and thermometers was installed in 2007 at the Carrel hut (3829 $\mathrm{m}$ a.s.1., Matterhorn, NW Alps). In 2010, in the framework of the Interreg 2007-2013 Alcotra project no. 56 MASSA, the monitoring system has been empowered and renovated in order to meet project needs.

In this paper, the data recorded by this renewed system between 6 October 2010 and 5 October 2011 are presented and 329 selected microseismic events are analysed. The data processing has concerned the classification of the recorded signals, the analysis of their distribution in time and the identification of the most important trace characteristics in time and frequency domain. The interpretation of the results has evidenced a possible correlation between the temperature trend and the event occurrence.

The research is still in progress and the data recording and interpretation are planned for a longer period to better investigate the spatial-temporal distribution of microseismic activity in the rock mass, with specific attention to the relation of microseismic activity with temperatures. The overall goal is to verify the possibility to set up an effective monitoring system for investigating the stability of a rock mass under permafrost conditions, in order to supply the researchers with
\end{abstract}

useful data to better understand the relationship between temperature and rock mass stability and, possibly, the technicians with a valid tool for decision-making.

\section{Introduction}

Rock-falls are among the most common and hazardous instability processes in high mountain environments: favoured by slope steepness, they are frightening because of their velocity and because of the difficulty to recognise precursory signals.

The identification of an efficient procedure for rock-fall warning is here traced back to the availability of field data deriving from monitoring of rock slopes.

However, the conventional slope monitoring techniques (e.g., displacement transducer arrays, inclinometers, geodetic and remote-sensing observation, etc.) are not always suitable for rock fall investigation since they: (1) can be very expensive; (2) can become difficult to apply over long periods of time; (3) can require that the location of the rupture surface is known; and (4) are not able to effectively investigate the precursory phenomena that may lead to a rock-fall. This latter point is particularly true when the monitoring is based on the measuring of the slope deformations; in fact, the rupture in rock material is a brittle mechanism accompanied by very small deformations that are difficult to detect. In this paper, geophones are proposed as the monitoring devices able to face and solve most of the above mentioned problems. 

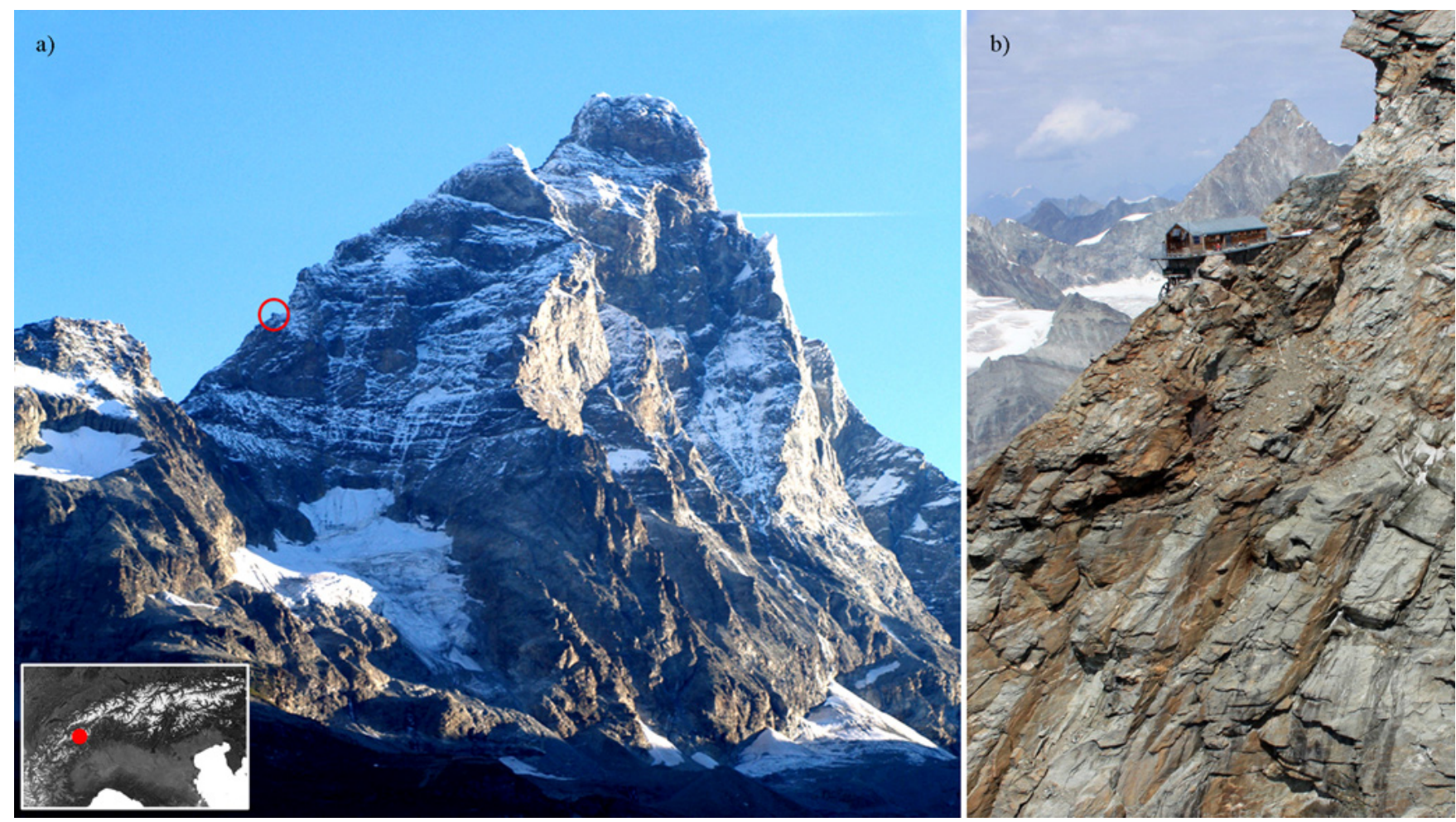

Fig. 1. Geographical context and location of the monitoring site: (a) the Matterhorn peak, the study site lies in the red circle; (b) detail of the J. A. Carrel hut.

Geophones allow the recording of ground vibrations that precede rock-falls, due to the initiation of cracks and coalescence of existing ones. Obert and Duvall (1942) were the first to observe the "ground vibration" process in the field, while studying the seismicity of rock-bursts in mines and tunnels. The phenomenon is nowadays much more clearly understood: the formation and propagation of cracks in rock materials is accompanied by a sudden release of stored elastic energy that propagates in the form of elastic waves. These latter can be detected, at the laboratory scale, by a suitable transducer array of acoustic emission (AE) sensors or by microseismic (MS) transducers, at the site scale (Lockner, 1993; Dixon et al., 2003; Kolesnikov et al., 2003).

The study of MS activity and the associated detection and interpretation techniques have developed considerably over the years. As a result, a better comprehension of the failure process and of the precursory patterns leading to collapse is nowadays made possible (e.g., Senfaute et al., 2003; Amitrano et al., 2005; Shiotani et al., 2006). Many efforts have consequently been devoted to the development of reliable rock slope monitoring systems based on this approach (Senfaute et al., 2009; Arosio et al., 2009; Levy et al., 2011).

The awareness of the problem of rock slope instabilities in high mountains was raised for alpine European countries in summer 2003, when an exceptional heat wave, accompanied by an unusually high number of rock-falls, hit central
Europe. On that occasion, a possible correlation was hypothesized between rock slope instabilities and enhanced permafrost degradation due to the anomalous temperature raise (Gruber et al., 2004).

The Interreg IIIA Alcotra Project n. 196 "PERMAdataROC", actuated in the period between March 2006 and June 2008, was aimed to investigate such a correlation and to identify suitable tools for monitoring rock slope deformation and instability in high elevation slopes. The Matterhorn (4478 m a.s.l., NW Italian Alps), a spectacular rock pyramid made of highly fractured gneisses and gabbros, was selected as the study site, in consideration of rock-falls and rock deformation documented in summer 2003 and because of the J. A. Carrel hut (3829 m a.s.1.), which offers the possibility of having a unique logistic base. A MS monitoring system and a thermometric monitoring system were then installed by CNR IRPI Torino, in cooperation with Regione Valle d'Aosta, and by ARPA Valle d'Aosta, respectively. Amitrano et al. (2010) and Occhiena (2011) present the description of the installations and the project outcomes.

In 2010, the start of the Interreg Alcotra Project no. 56 "MASSA" allowed the Matterhorn MS monitoring system to be restored by CNR-IRPI Torino, with the financial support of Regione Valle d'Aosta. Three new superficial low frequency geophones were added to the system configuration, while the acquisition and transmission systems were 


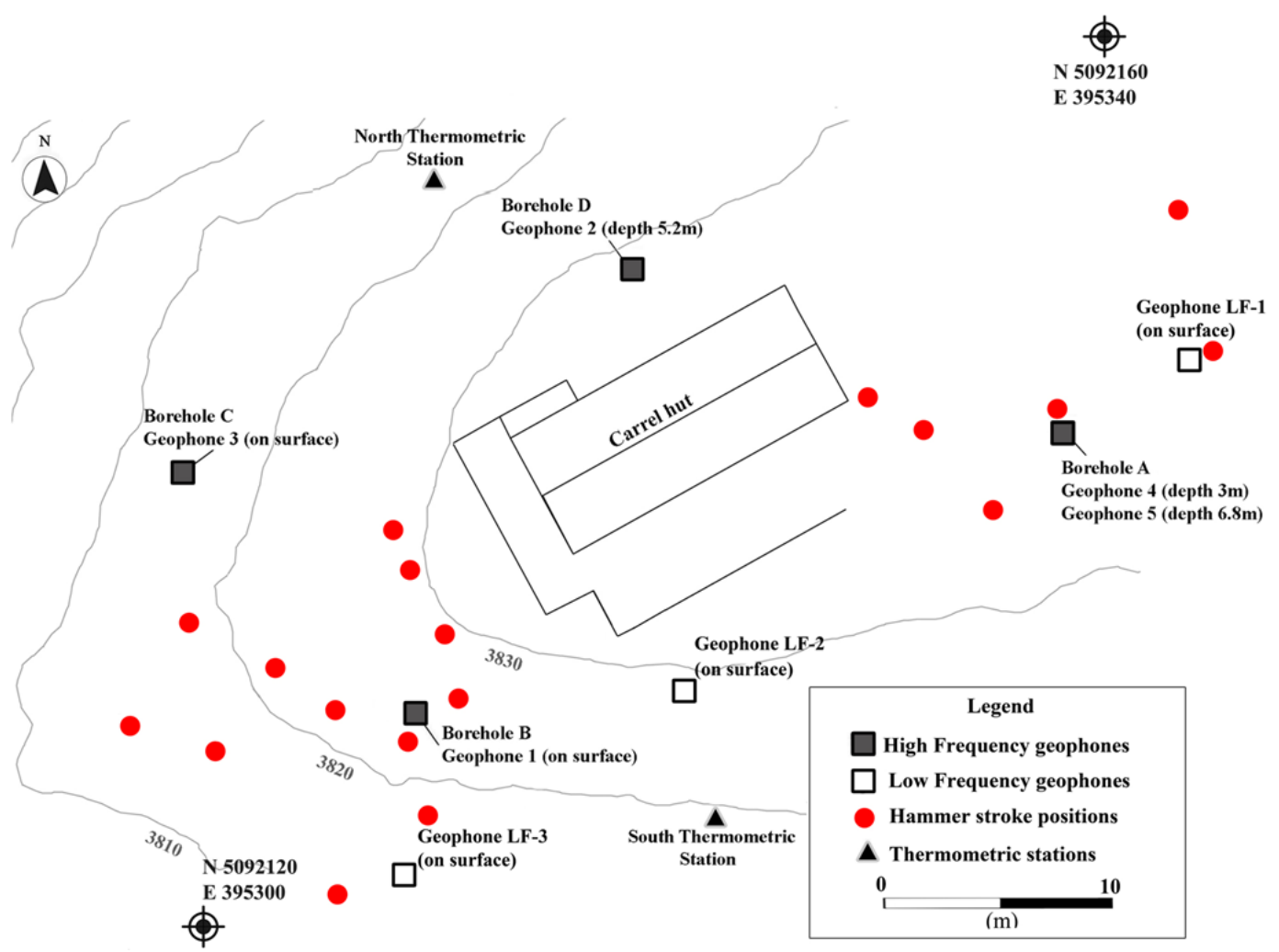

Fig. 2. The J. A. Carrel hut and the position of the geophones, of the hammer strokes and of the thermometric stations.

empowered. In the present paper, the characteristics of the empowered MS monitoring system are described and preliminary data processing, including the classification of the first recordings, the identification of the significant microseismic events and the analysis of their distribution in time are presented. Furthermore, MS data are compared with thermometric ones, in order to investigate the influence of climatic factors on rock slope dynamics.

\section{Description of the MS monitoring system}

The characteristics of the MS monitoring system installed in 2007, the reasons of the site choice and the details of the geomorphological setting of the area are detailed in Amitrano et al. (2010). Hereinafter, the improvements and the characteristics of the empowered and renovated system are presented.

The MS monitoring system installed at the J. A. Carrel hut, on the south-west ridge of the Matterhorn (Fig. 1), is a basic/digital multi-channel monitoring system. It is presently composed of five triaxial high frequency geophones, three triaxial low frequency geophones, a power supply group connected to solar panels, a 24-channel acquisition system and a GPS receiver. The system is equipped with a wireless data transmission system which connects the data-logger (placed inside the hut) to the village of Breuil-Cervinia, where the data are periodically downloaded.
The type, number and position of the MS sensors were selected considering three main issues:

1. the high degree of fracturation characterising the rock mass sustaining the J. A. Carrel hut;

2. the purpose of locating the sources of MS activity recorded around the site;

3. the logistical and morphological constraints of the site (steep slopes, frequent hikers, severe weather conditions).

The High Frequency (HF) geophones are five triaxial sensors with a natural frequency of $100 \mathrm{~Hz}$. Each of them is installed with the x-component aligned with the East, the y aligned with the North and the z-aligned with the vertical direction. Three of these geophones are installed in boreholes and are fixed at the base to warrantee the coupling between the rock and the sensor. The Low Frequency (LF) geophones are three triaxial sensors with a natural frequency of $4.5 \mathrm{~Hz}$ and are oriented as the HF geophones (i.e., x-East, y-North, z-vertical). Further specifications of the geophone and their positioning description are summarized in Tables 1 and 2, respectively. Finally, Fig. 2 shows the present spatial distribution of the geophone network. 

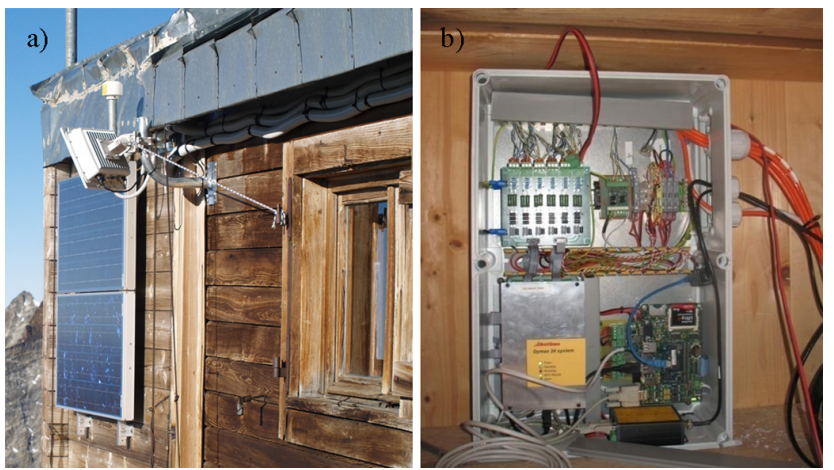

Fig. 3. (a) The solar panels, the GPS and the aerial radio installed outside the Carrel hut; (b) the acquisition system installed inside the hut (photo by Signori and Bani, 2010).

The power supply group is made out of two solar panels ( $80 \mathrm{~W}$ photovoltaic modules per panel) mounted outside the hut (Fig. 3a) and connected to a storage battery of $100 \mathrm{Ah}$.

The acquisition system is powered by a direct voltage ranging from 10.5 to $18 \mathrm{~V}$ and is composed by 4 acquisition boards of 6 channels each (Ch. 1-6 have been connected to the LF geophones, Ch. 7-24 to the HF geophones) (Fig. 3b). Each board is equipped with a Digital Signal Processor (DSP) that starts the automatic algorithm for event recognition, records the data as a circular buffer on a RAM (Random-Access Memory) and converts the recorded analogical signals into a digital signals. The DSP allows to set different triggering threshold for each channel: high-pass, band-pass or low-pass filters. Further specifications of the acquisition system are summarized in Table 3 .

The GPS receiver allows the synchronizing of the time reference of all the units that form the monitoring system: this is necessary to guarantee that data, which are transferred from the acquisition system to the local computer through a LAN (Local Area Network) network and are stored on a compact flash card, are recorded simultaneously from all the channels.

\subsection{Calibration tests of the MS monitoring system: description and analysis}

Once the installation was completed, the verification procedure of the proper functioning of the monitoring system has been carried out by energizing some points of the rock mass through a hammer (Fig. 4) and verifying their correct recording by the system.

The 2007 installation was followed by the energization at 4 positions, that was carried out, initially, with the only purpose of testing the installed instrumentations. However, since the location of the MS natural sources can provide important information on the spatial distribution of weakness zones in the rock slope, only if an accurate knowledge of the velocity of the acoustic waves crossing the medium is available, it emerges that the re-location of the above artificial
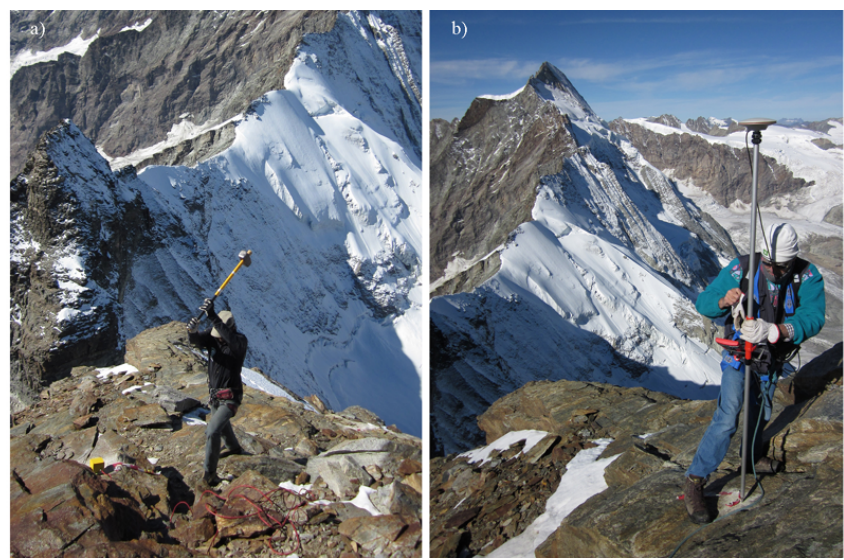

Fig. 4. Calibration tests of the MS monitoring system: (a) the hammering of the rock surface; (b) the topographic survey of the point.

MS sources can also contribute in determining the necessary propagation velocity model.

From a numerical point-of-view, it can be observed that common seismic location tools usually allow the implementing of a homogeneous or multilayered velocity model. But, since microseismic networks usually investigate small regions in space that can be affected by a heavy fractured rock material, a more accurate knowledge of the velocity field in the crossed medium is required. In case of an irregular topography, as an example, the velocity model has to include both air and rock. The computation of a heterogeneous velocity model that allows the changing of the velocity value at each single point, according to the local average characteristics of the rock mass becomes particularly important (Occhiena, 2011). For this reason, 18 georeferenced points, distributed as uniformly as possible in space (Fig. 2), were selected for hammering in Autumn 2010 to provide a larger number of information for the creation of the abovementioned velocity model. In particular, the hammering test was repeated at least three times at each georeferenced point. For each test the source time was recorded by the $\mathrm{x}$-channel of a LF geophone, to allow the following re-location of the recorded signal using the time of arrival location technique.

The spectral characteristics of the hammer stroke signals recorded at the geophones result in the following ranges:

- HF geophones, the dominant frequency is between 300 and $800 \mathrm{~Hz}$; some spectral components are also visible around $1000 \mathrm{~Hz}$;

- LF geophones, the dominant frequency is below $100 \mathrm{~Hz}$; some significant components are also visible at higher frequency, but almost no significant frequencies exist above $500 \mathrm{~Hz}$. 
Table 1. Specifications of the installed geophones.

\begin{tabular}{lll}
\hline & High Frequency geophones & Low Frequency geophones \\
\hline Model & Mark L40A-2 & VELOGET.3D \\
Natural Frequency $[\mathrm{Hz}]$ & 100 & 4.5 \\
Working frequency range $[\mathrm{Hz}]$ & $80 \div 2000$ & $4 \div 500$ \\
Type & triaxial transducers & triaxial transducers \\
Transduction constant $\left[\mathrm{V}\left(\mathrm{ms}^{-1}\right)^{-1}\right]$ & 23.6 & 32 \\
Damping & 0.7 & 0.7 \\
Dimensions [mm] & Diam. 50; Height 186 & Length 150; Depth 75; Height 100 \\
Waterproof $[\mathrm{m}]$ & 200 & 200 \\
Polarity & Positive for movements in the axis direction & Positive for movements in the axis direction \\
\hline
\end{tabular}

Table 2. Position of the geophones.

\begin{tabular}{llllll}
\hline Geophone ID no. & Location & Installation yr & East $(\mathrm{m})$ & North $(\mathrm{m})$ & Elevation $(\mathrm{m})$ \\
\hline LF-1 & On surface & 2010 & 395343.868 & 5092145.637 & 3844.72 \\
LF-2 & On surface & 2010 & 395321.252 & 5092130.866 & 3827.059 \\
LF-3 & On surface & 2010 & 395308.866 & 5092122.597 & 3818.694 \\
2 & Borehole D $(-5.2 \mathrm{~m})$ & 2007 & 395318.98 & 5092149.447 & 3825.66 \\
3 & On surface & 2007 & 395299.325 & 5092140.638 & 3818.61 \\
1 & On surface & 2007 & 395309.481 & 5092130.173 & 3823.29 \\
4 & Borehole A $(-3.0 \mathrm{~m})$ & 2007 & 395338.093 & 5092142.653 & 3831.71 \\
5 & Borehole A $(-6.8 \mathrm{~m})$ & 2007 & 395338.093 & 5092142.653 & 3827.91 \\
\hline
\end{tabular}

Table 3. Specifications of the acquisition system installed inside the hut.

\begin{tabular}{|c|c|}
\hline Sampling frequency & $8 \mathrm{kHz}$ \\
\hline Gain of the amplifiers & $38 \mathrm{~dB}$ \\
\hline $\begin{array}{l}\text { Vertical dynamics (number of } \\
\text { sampling points between the } \\
\text { minimum and the maximum } \\
\text { amplitude) }\end{array}$ & 16 bits \\
\hline Minimum and maximum amplitude & \pm 3 Volts \\
\hline Mean value of noise & $0.002 \mathrm{~mm} \mathrm{~s}^{-1}$ \\
\hline
\end{tabular}

A good correlation has been found between the source distance from the sensors and the frequency content of the signal. In particular, the frequency content has been observed to decrease with the increase of the distance, due to the attenuation of the high frequency components.

The analysis of the amplitudes has evidenced that the signals are characterised by high amplitude and low noise as close as the sensor and the source were. In fact, the Signalto-Noise-Ratio (SNR), which is the ratio between the signal average amplitudes during a defined time interval and the noise amplitude, resulted for each geophone as follows:

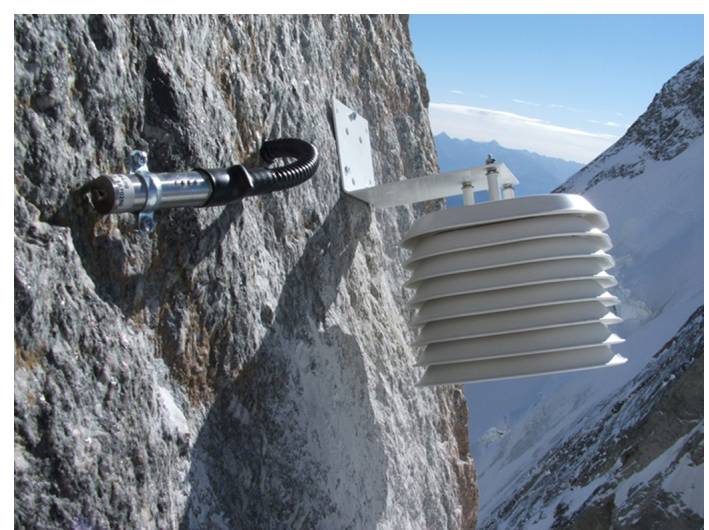

Fig. 5. The instruments installed on the near vertical rock-walls underling the J. A. Carrel hut: in the foreground the mini-datalogger M-Log6 for the ground surface temperature measures and the radiation-shield hosting the M-Log5 for the measure of the air temperature.

SNR $\left\{\begin{array}{cc}>5 & \text { distance source/geophone } \leq 5 \mathrm{~m} \\ 1 \div 5 & 5 \mathrm{~m}<\text { distance source/geophone }<10 \mathrm{~m} \\ \text { ND* } & 10 \mathrm{~m}<\text { distance source/geophone }<20 \mathrm{~m} \\ <0.5 & \text { distance source/geophone } \geq 20 \mathrm{~m}\end{array}\right.$

(* a value cannot be defined since both good and bad signals can be found). 


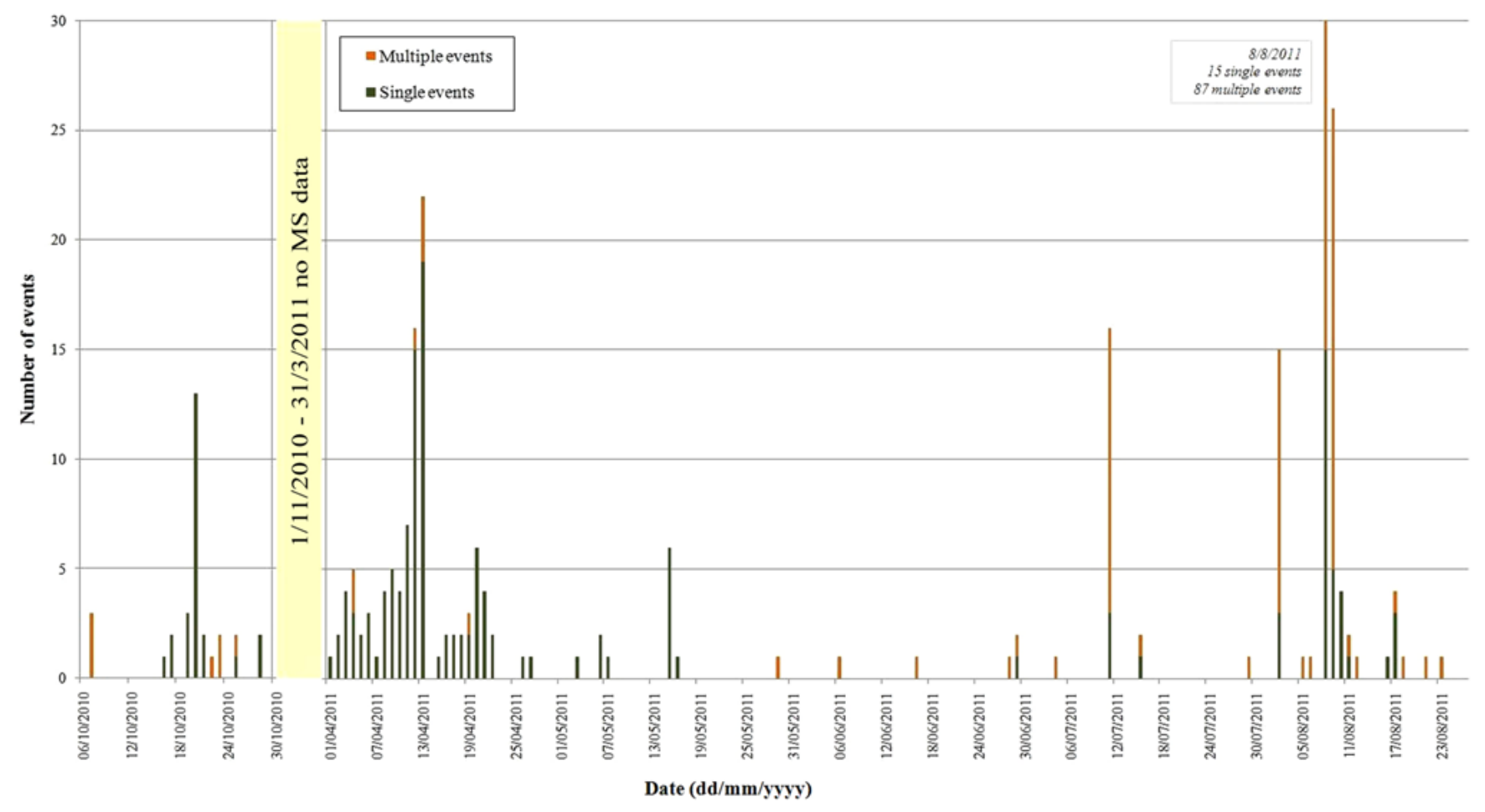

Fig. 6. Temporal distribution of the 329 events occurred between 6 October 2010 and 23 August 2011, classed as single or multiple events.

The above observations confirm the existence of a correlation between the signal characteristics (amplitude and frequency content) and the wave ray paths. In a heavy fractured rock mass, as the Matterhorn peak, one would expect that the relation between the distance and frequency and the amplitude attenuations may get lost, due to the influence of the rock discontinuities on the paths followed by the wave to reach the sensor. On the contrary, the preliminary analyses of the hammer strokes have evidenced the presence of a correlation between the signal frequency content, the recorded amplitude and the distance of the sensor from the source. This relation is visible both on the HF and on the LF geophones, even though the frequency attenuation is more difficult to be appreciated on these latter.

\section{Description of the thermometric monitoring system}

Air and surface rock temperature have been monitored since 2006 by the Regional Agency for the Environmental Protection (ARPA) in the surroundings of the Carrel Hut, within the framework of the permafrost monitoring network of the Valle d'Aosta region. The measuring points are located on the near vertical rock walls underlying the hut, some tens of metres apart from this latter, on both sides of the ridge, 1 point on the South face and 1 point on the North-West face (Fig. 2).

The surface rock temperature was measured every hour at 3 different depths $(0.03,0.30$ and $0.55 \mathrm{~m})$ by means of minidatalogger Geoprecision M-Log6 from 2006 to 2010. During the summer of 2011, these instruments were replaced by an improved version of the datalogger (Geoprecision iLogII) that is equipped with a GPRS module for the daily transmission of the recorded data. At the same time, the air sensor of the South station was removed, while the air sensor of the North-West station was replaced with a M-Log5 minidatalogger by Geoprecision (Fig. 5). This sensor is housed within a radiation shield installed on the rock-wall in order to avoid the influence of the direct solar radiation. During the time span of interest for the present analysis only air temperature data are available due to the discontinuous functioning of the rock temperatures system.

\section{Microseismic dataset analysis and classification}

It is evidenced here that, due to the difficult weather conditions, the 2011 intense climbing season on the Matterhorn started only in September; as a consequence, no relevant human presence should have influenced the recordings analysed here.

The classification of the MS signals recorded by the Matterhorn MS monitoring system, based on the amplitudes and the main characteristics in time and frequency domain of the signals recorded at each geophone, has been first carried out. A trace classification allows the screening of the quality and the properties of the recordings at each geophone and can contribute to the comprehension of the possible correlation between MS rate and inelastic strain rate. Consequently, this 
procedure can be considered the first step in the identification of possible rock weakness areas and of eventual precursory phenomena that may bring from the progressive formation of macroscale discontinuities up to the final collapse of slope portions.

Since the classification of recorded signals is a sensitive and time-consuming task (Spillmann et al., 2007; Deparis et al., 2008; Levy et al., 2011; Occhiena, 2011), it is important that the triggering parameters of the system are set to guarantee the monitoring targets, preventing the recording of a large number of meaningless signals. The Matterhorn monitoring system records an event when a threshold value (triggering condition) is exceeded on a selected number of channels. The recording covers a time interval of $3 / 5 \mathrm{~s}$ after the trigger. The calibration of the threshold value was necessary after the installation of the monitoring system to avoid the above mentioned problem. After some tests, a triggering threshold equal to $0.01 \mathrm{~mm} \mathrm{~s}^{-1}$ to be exceeded simultaneously on at least 6 channels was set. Initially, channels from both LF and HF geophones were able to cause the recording start. This produced the recording of a large number of MS events that had no-signal on HF geophones and caused a fast memory saturation; as a consequence, since 1 April 2011 LF geophones were excluded from the triggering condition.

A number of 649 events were recorded in the period between 6 October 2010 and 5 October 2011 (the whole period can be analysed since the value of $0.01 \mathrm{~mm} \mathrm{~s}^{-1}$ was never modified, even if LF geophones were excluded from the triggering condition after April 2011). However, this registration activity was discontinuous: (i) between November 2010 and April 2011, a power supply malfunction caused a loss of data; (ii) from 26 August 2011 geophones 3 and 1 were out of order (an in situ maintenance inspection showed that one of the acquisition board had been damaged), consequently the signals recorded after this date were not analysed. As a result, a subset of 540 events was selected. But, from the successive analysis, it emerged that 211 of these events present harmonic oscillations, anomalous instantaneous or multiple picks and mute channels which can be ascribed to electrical disturbances. All things considered, only 329 events, recorded from 6 October 2010 to 23 August 2011, have actually been analysed and classified.

The first qualitative observation of the recordings on each geophone led to identifying two main classes:

1. Only one event exists in each recording (i.e., the threshold is exceeded only once in the recording): 167 recordings have this characteristic (Fig. 7);

2. More than one event exists in each recording (i.e., the threshold is exceeded more than once in the recording): 162 recordings have this characteristic (Fig. 10).

In Fig. 6 the histogram reported the daily number of recordings subdivided per class. The analysis of this distribution evidences that the daily MS activity does not follow a unique
Table 4. Daily event concentrations during the period between 6 October 2010 and 23 August 2011.

\begin{tabular}{llll}
\hline $\begin{array}{l}\text { Date } \\
(\mathrm{dd} / \mathrm{mm} / \text { yyyy) }\end{array}$ & $\begin{array}{l}\text { Total number } \\
\text { of events }\end{array}$ & $\begin{array}{l}\text { Single } \\
\text { events }\end{array}$ & $\begin{array}{l}\text { Multiple } \\
\text { events }\end{array}$ \\
\hline $20 / 10 / 2010$ & 13 & 13 & 0 \\
$12 / 04 / 2011$ & 16 & 15 & 1 \\
$13 / 04 / 2011$ & 22 & 19 & 3 \\
$11 / 07 / 2011$ & 16 & 3 & 13 \\
$02 / 08 / 2011$ & 15 & 3 & 12 \\
$08 / 08 / 2011$ & 102 & 15 & 87 \\
$09 / 08 / 2011$ & 26 & 5 & 21 \\
\hline
\end{tabular}

trend. Apart from some particular daily recording concentrations (see Table 4 for more details), the rate of daily events is quite regular from October 2010 to April 2011. On the contrary, the trend is less regular and is characterised by many days in which no recordings occurred and by some exceptional daily event concentrations (Table 4) from the end of April 2011 to the end of August 2011. Concerning multiple events, it can also be observed that their occurrence largely increases after 11 July 2011.

\subsection{Class 1: single events}

A first screening of the single events was performed with a MATLAB-based code to analyse the signal amplitudes at each channel of the sensors and to classify the recorded traces on the basis of the Signal-to-Noise-Ratio (SNR). The method used to compute the SNR is based on the Short Term Averaging/Long Term Averaging (STA/LTA) ratios (Occhiena, 2011).

STA/LTA is the ratio between the average amplitude of the signal calculated on a short time window (STA) of $0.02 \mathrm{~s}$ and the average amplitude of the signal calculated on a long time window (LTA) of $0.09 \mathrm{~s}$. Both these average values are computed as the L1 norm, that is the average of the absolute amplitude values.

The following parameters are used as inputs of the code:

1. the STA/LTA Threshold, which is the value that runs the pre-trigger mode;

2. the STA/LTA Pre-Trigger, which is the time interval (in seconds) that is picked up by the code from the beginning of the event when the STA/LTA ratio exceeds the fixed threshold.

The code performs a loop that scrolls the signal computing the STA/LTA ratio within a floating window. The loop stops and picks up the starting time of the event when the threshold value is exceeded. At this point, a second loop is performed that identifies the STA/LTA ratio when it becomes lower than the fixed threshold and assumes the time of this occurrence as the end of the event. 

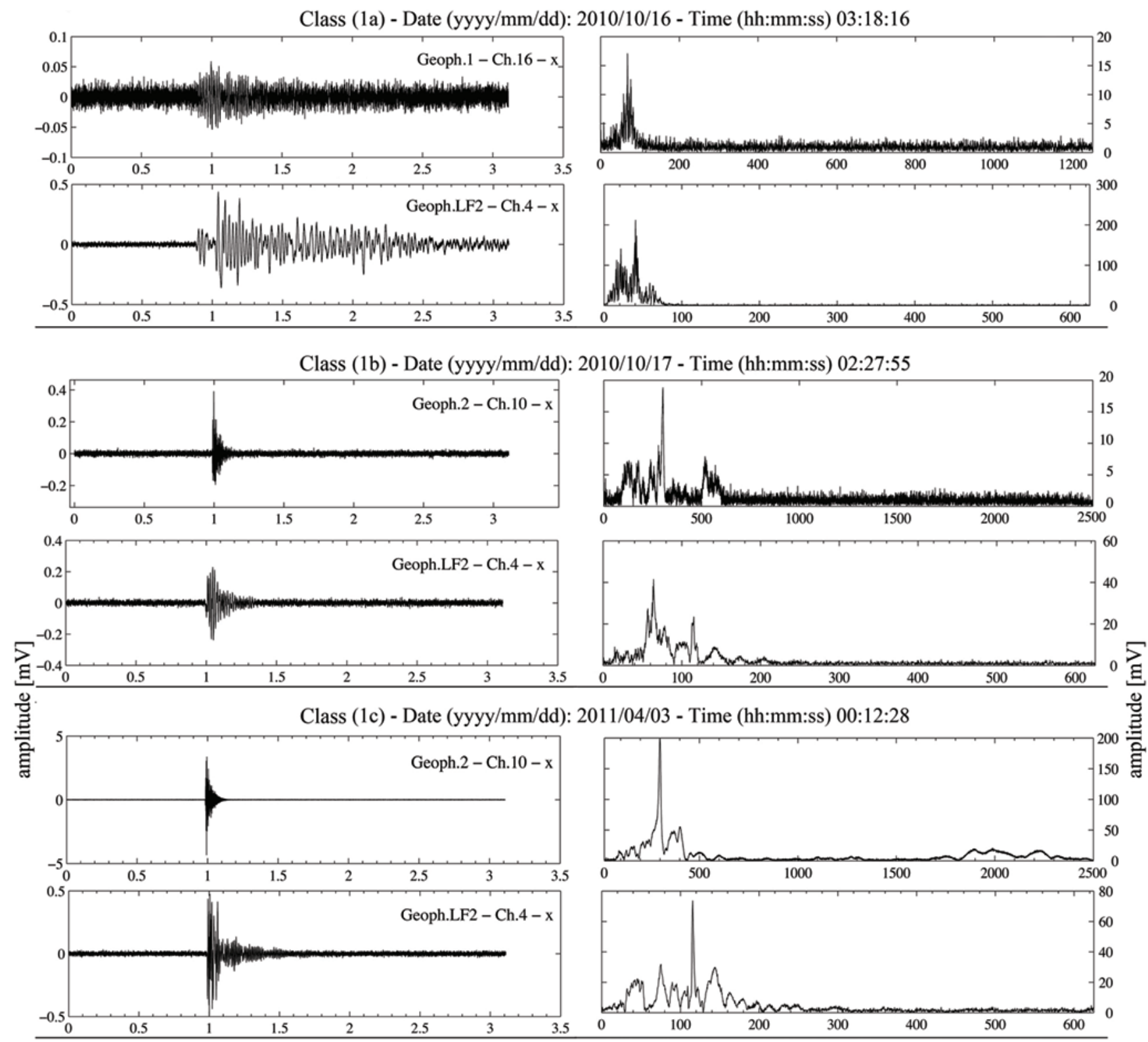

Class (1d) - Date (yyyy/mm/dd): 2011/04/16 - Time (hh:mm:ss) 21:22:10
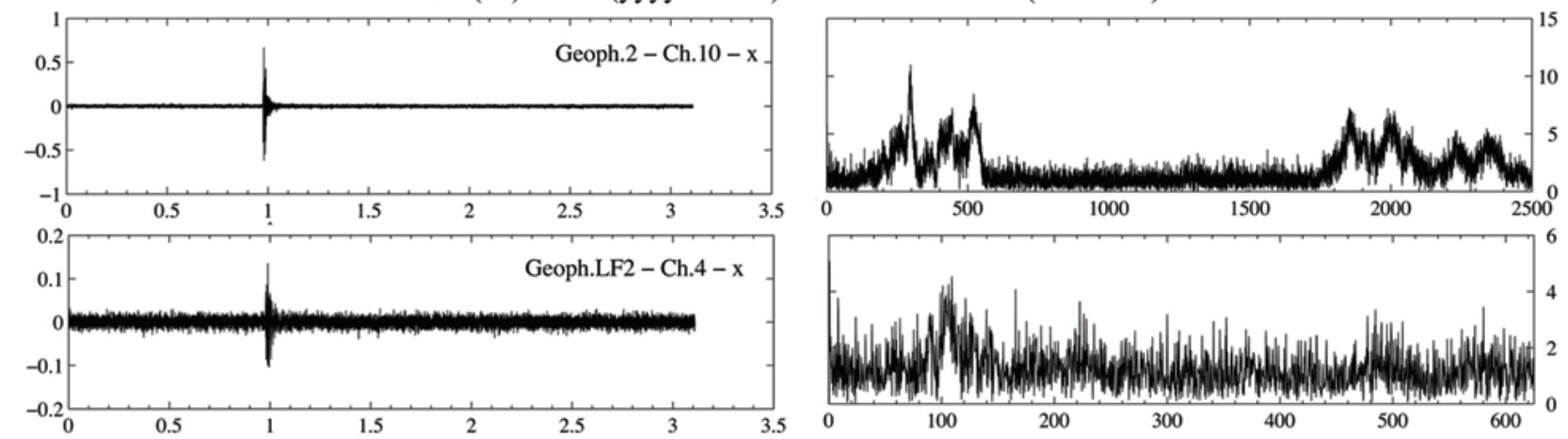

a) time $[\mathrm{s}]$

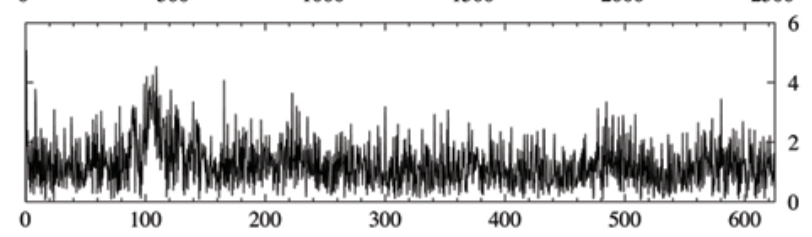

b) frequency $[\mathrm{Hz}]$

Fig. 7. Characteristics of the identified four classes of single events: example of a signal recorded by an HF and a LF geophone (a) in time domain and (b) in frequency domain. 
Table 5. Input parameter values used in the MATLAB-based code for the automatic event detection.

\begin{tabular}{ll}
\hline Parameter & Value \\
\hline STA/LTA Threshold & 4 and 10 \\
STA/LTA Pre-trigger & $0.5 \mathrm{~s}$ \\
\hline
\end{tabular}

In Table 5 the values of the input parameters chosen for the Matterhorn data are shown: in a first phase, a tentative value for the threshold was adopted equal to 4 and some classes of events identified. Subsequently, the threshold value was set equal to 10 and a further class grouping event characterised by a particularly high SNR was identified.

The automatic detection performed by the MATLABbased code allowed to subdivide the single event class into four further categories (Fig. 7):

1. class (1a): events with a SNR $<0.5$ on the HF geophones and a SNR $>4$ on the LF geophones;

2. class (1b): events with a SNR $>4$ on both HF and LF geophones;

3. class (1c): events with a SNR $>10$ on both HF and LF geophones;

4. class (1d): events with a SNR $>4$ on the HF geophones located in the western side of the network (geophones 1 , 2 and 3) and by a SNR $<0.5$ on both the HF geophones located in the eastern side of the network (geophones 4 and 5) and the LF geophones.

The spectral characteristics of each of these classes were investigated, computing the Fourier transform of the signal of each geophone (Fig. 7b). It emerged that:

- the class (1a) groups low frequency signals: the traces recorded by the HF geophones (with a low SNR that makes the event identification difficult both in time and frequency domain, except on geophones 1 and 3) are characterised by a low frequency content with a peak below $100 \mathrm{~Hz}$. The Fourier transform of the traces recorded by the LF geophones is characterised by a dominant frequency of about $50 \mathrm{~Hz}$.

- the class (1b) is characterised by events with a frequency content that ranges between $50 \mathrm{~Hz}$ and $400 \mathrm{~Hz}$ : the low frequency components are clearly visible on the LF geophones. The Fourier transform of the signals recorded by the LF geophones shows a dominant frequency at $80 \mathrm{~Hz}$ and some common components at $100 \mathrm{~Hz}$; the dominant frequency of the signals of the HF geophones ranges between $150 \mathrm{~Hz}$ and $250 \mathrm{~Hz}$. Some common components are also visible at $100 \mathrm{~Hz}$ and $300 \mathrm{~Hz}$;
- the class (1c) is characterised by events with a high frequency content: this is particularly evident on the HF geophones, where the Fourier transforms show a dominant frequency at $400 \mathrm{~Hz}$ with some components at $1000 \mathrm{~Hz}$ and $2000 \mathrm{~Hz}$ (visible on the geophones 2, 3 and 5). The dominant frequency of the LF geophones is $80 \mathrm{~Hz}$, but some higher components are clearly visible in the range between $100 \mathrm{~Hz}$ and $200 \mathrm{~Hz}$;

- the class (1d) groups a small number of events which are probably generated in the western side of the network: the signals are weak both in the time and frequency domains on the geophones located in the eastern side of the hut (geophones 4 and 5 and LF geophones). At the geophones 1, 2 and 3 the dominant frequency ranges between $300 \mathrm{~Hz}$ and $400 \mathrm{~Hz}$ and some significant components are also visible in the range between $1500 \mathrm{~Hz}$ and $2000 \mathrm{~Hz}$.

The time distribution of the events represented in Fig. 8 is evidence of a large number of the event peaks from October 2010 and April 2011 that belongs to classes (1b) and (1c). In April 2011, a significant increase of class (1d) events can also be observed. On the contrary, in August 2011 the recorded events only belong to class (1b). The cumulative events for class (1a) is the only one showing a regular and moderate increase during the whole recording period, this evidence shows that the recording of this type of event is quite rare and is randomly distributed in time.

The amplitude assigned to each geophone was computed, for each of the 167 single events, as the average of the maximum amplitude on each channel (Fig. 9). The seismic energy was computed for each channel as:

$E_{\mathrm{C}}=\int|A(t)|^{2} d t$

where $E_{\mathrm{C}}$ is the energy detected by each channel and $A(t)$ represents the instantaneous amplitude. The energy assigned to the geophone was then computed as follows:

$E_{\mathrm{G}}=\sqrt{E_{\mathrm{Cx}}^{2}+E_{\mathrm{Cy}}^{2}+E_{\mathrm{Cz}}^{2}}$

where $E_{\mathrm{Cx}}, E_{\mathrm{Cy}}$ and $E_{\mathrm{Cz}}$ are the seismic energies detected, respectively, by the $\mathrm{x}-\mathrm{y}, \mathrm{y}$ - and $\mathrm{z}$-geophone channels.

Comparing the cumulative distribution of the maximum amplitude and the seismic energy (Fig. 9) with that of the number of events (Fig. 8), it emerged that the event concentrations which occurred during October 2010 and April 2011 corresponded to different increments of the amplitude and of the seismic energy at each geophone. Among the HF geophones, the geophones 1 and 3 are interested by the higher increments, especially corresponding with the peak of events of April 2011. The cumulative distributions of the maximum 


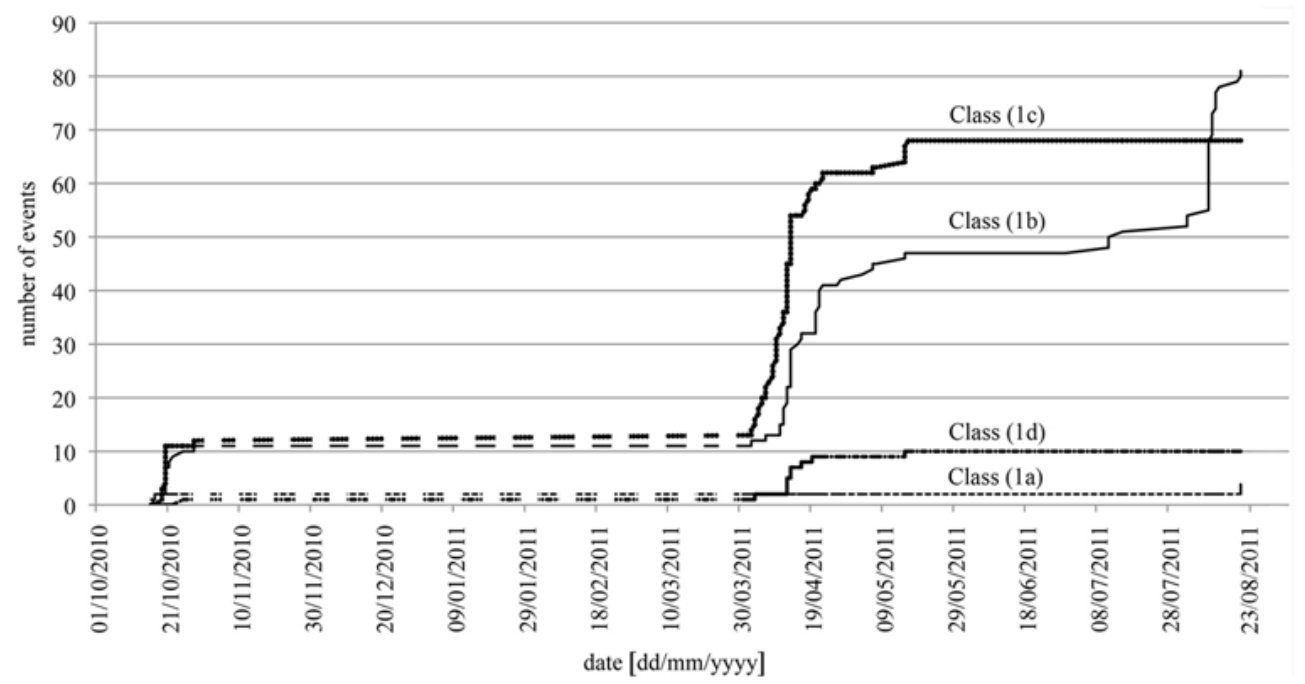

Fig. 8. Cumulative distribution of the number of events characterising each type of single event class. The dashed lines between 1 November 2010 and 31 March 2011 represent the no-data period.

amplitude detected by the HF geophones 2 and 4 (Fig. 9a) show a homogeneous rate of increment between them until the end of June 2011. The concentration of MS data recorded at the beginning of August 2011 (Fig. 6) caused a peak of activity on the geophone 4 rather than on geophone 2 . Observing the distributions of the seismic energy (Fig. 9b) it emerges that even if geophone 2 is characterised by a total cumulate maximum amplitude lower than geophone 4, nevertheless its accumulated seismic energy is higher than that of geophone 4. This means that the maximum amplitude on a single channel can reach a high instantaneous peak value, which can be smoothed by averaging in the computation of the seismic energy. As a consequence, signals showing a high instantaneous amplitude peak can accumulate an energy content equal or even lower than that of traces with a maximum amplitude near to the mean value.

The HF geophone 5 is characterised by the lowest cumulative increment of both amplitude and energy.

Among the LF geophones, the geophone LF1 accumulates the highest increments of amplitude and energy in the crisis of both October 2010 and April 2011. The geophones LF2 and LF3 follow.

Since the energy, depending on the amplitude, decreases with the increase of the distance from the source, it can be assumed as a preliminary estimator of the source distance and, given the spatial distribution of the sensors, also of the source location. As a consequence, since the highest energy increments can be observed on the cumulative distributions of amplitude and energy for the superficial geophones (both HF and LF), while similar but lower increments can be observed for the deep geophones (geophones 2, 4 and 5), most of the energy of the single events must have been generated by superficial sources.
From the comparison of the general trend of the seismic energy cumulated by the LF and by the HF sensors during the month of August 2011, it emerges that a major increment rate is visible on the LF geophones, starting from the beginning of June to the end of the investigated period. This can confirm the above mentioned observation: the class $1 \mathrm{~b}$, characterising the larger part of events recorded after June 2011 (Fig. 8), group events with spectral components between $50 \mathrm{~Hz}$ and $400 \mathrm{~Hz}$, which represents a frequency range lower than that of the other classes.

\subsection{Class 2: multiple events}

As mentioned in the beginning of Sect. 3, 162 of the recorded occurrences are characterised by a sequence of impulsive signals and have been classed as multiple events. This class of events can be subdivided in two further categories (Fig. 10):

1. events characterised by a low SNR and a succession of two or three impulsive signals in the same recording;

2. events characterised by a variable SNR and a long signal fluctuation composed by a sequence of peaks in the same recording.

The frequency content of these two classes is quite homogeneous: in both cases the dominant frequency ranges between 100 and $300 \mathrm{~Hz}$ for the HF geophones and between 50 and $150 \mathrm{~Hz}$ for the LF geophones.

The cumulative distributions in time of the amplitude and of the seismic energy (Fig. 11) show an increment at each geophone corresponding to the peaks of events which occurred in October 2010, April 2011 and July-August 2011 (Fig. 6). 
a)
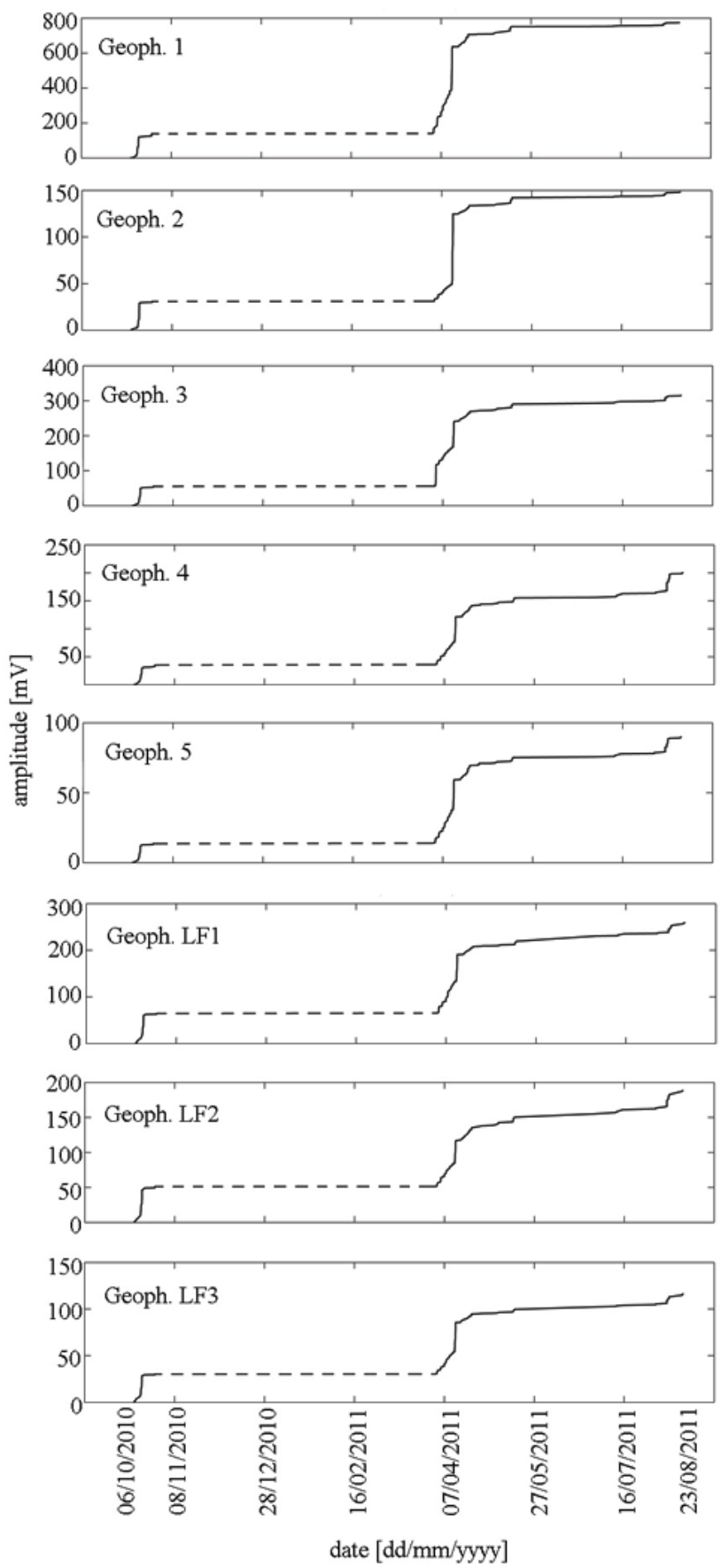

b)
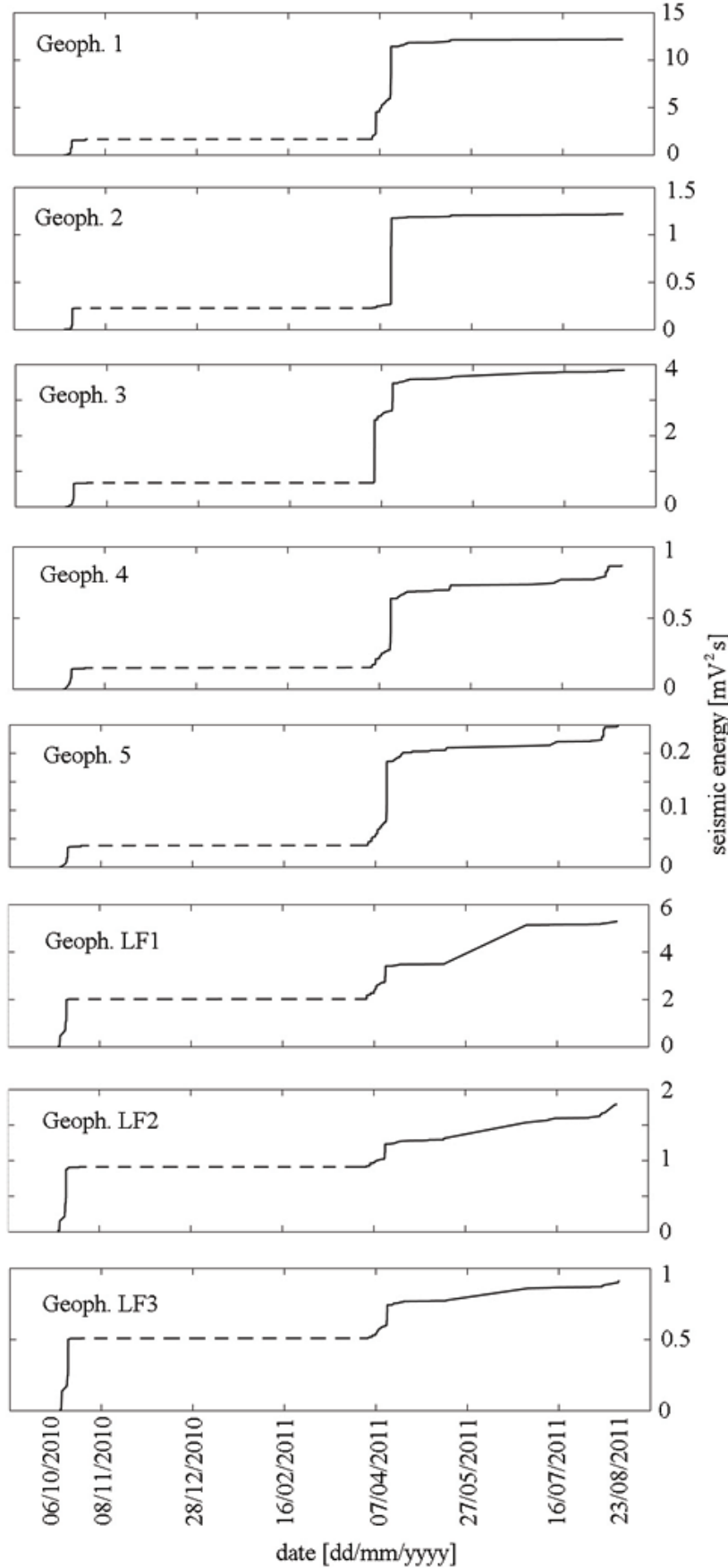

Fig. 9. Cumulative distribution of the (a) maximum amplitude and (b) seismic energy of the 167 single events recorded by each geophone. The dashed line represents the no-data period.

The multiple events recorded during October 2010 were mainly recorded by the HF geophone 2 and by the three LF geophones. On the contrary, the crises of April 2011 and July-August 2011 are clearly visible on the distributions of the maximum amplitudes cumulated by all the geophones. The HF geophone 1 is characterised by the highest increments of both amplitude and seismic energy due to the multiple event concentration observed in some days of April 2011.

The crisis of July 2011, in particular the exceptional event concentration occurred on 12 July 2011 (Fig. 6), is visible on the distributions of the cumulated amplitude of all the 

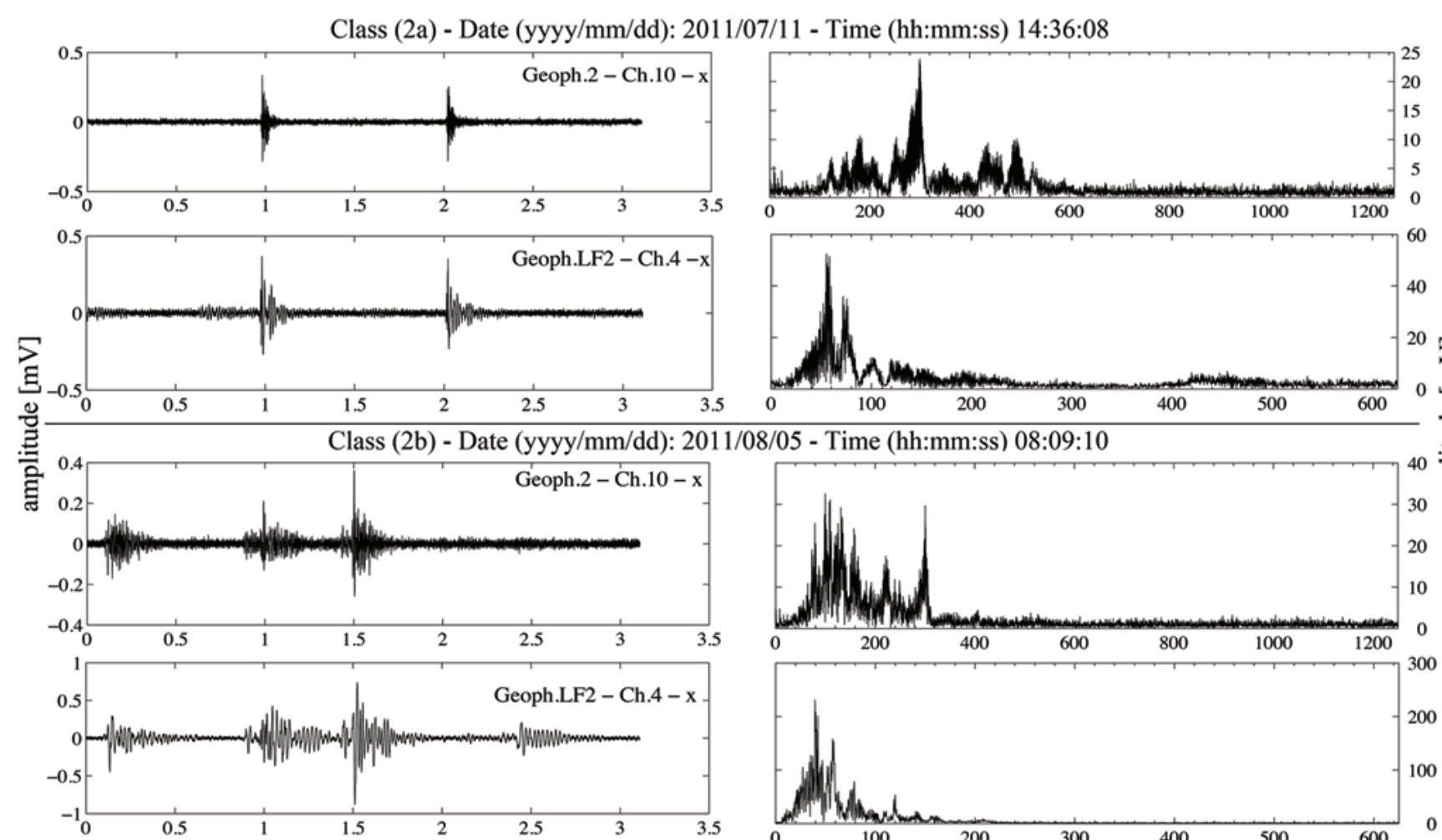

a) time [s]

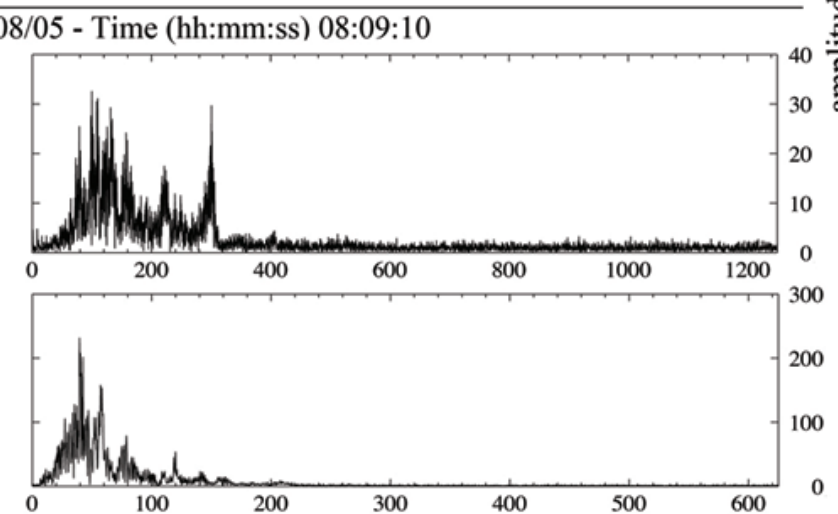

b) frequency $[\mathrm{Hz}]$

Fig. 10. Characteristics of the two classes of multiple events: example of a signal recorded by an HF and a LF geophone (a) in the time domain and (b) in the frequency domain.

geophones, but caused an accumulation of seismic energy mainly on the LF geophones (Fig. 11).

The peak of MS activity recorded at the beginning of August 2011 caused the highest increment on the cumulated amplitude and seismic energy of the geophone 4; on the contrary, the trend of the curves computed for the LF geophones is very similar after July 2011, showing a homogeneous rate of increment till the end of the investigated period.

The analysis of the cumulative amplitude and the seismic energy recorded by each geophone shows a less significant relation between the sensor and the source positions than for the single events (see Sect. 4.1). However, it is possible to observe that both of the HF and LF geophones located in the South-Western side of the network have recorded the multiple signals with the highest amplitudes and energies. Moreover, the seismic energy is observed to be higher on the LF geophones than on the HF.

Since the analysis of the frequency content of the multiple events (Fig. 10) has confirmed that this class of events is characterised by low frequency traces (no components are visible above $500 \mathrm{~Hz}$ ), this may indicate that the source of the multiple events is at-depth and far from the sensor array. But, the existence of signals with a SNR that is higher for superficial geophones than for at-depth geophones is against the above hypothesis. As a consequence, the multiple low frequency signals might be due not to the filtering of signals coming from at-depth and far sources, but to the existence of a particular and maybe superficial rupture mechanism.

The information available in the literature for sites where a microseismic monitoring system is installed together with a direct observation of the source mechanisms (e.g., Deparis et al., 2008; Levy et al., 2011) suggest a possible explanation for the multiple recorded traces. In particular, the events of class (2a) could have been caused by a short succession of cracking events, while those of the class ( $2 b$ ) could have been produced by a sequence of falling blocks.

\section{Comparison between MS data and air temperature records}

In Fig. 12, the superposition between the number of daily MS events and the mean daily air temperature recorded on the North-West side of the ridge is used to investigate the possible correlation between rock deformations and temperature variations. In order to frame this comparison within a wide climatic context, also a plot of the air temperature anomalies recorded in the area of the Matterhorn during the Hydrological Year (HY) 2011 is provided in Fig. 13. 
a)
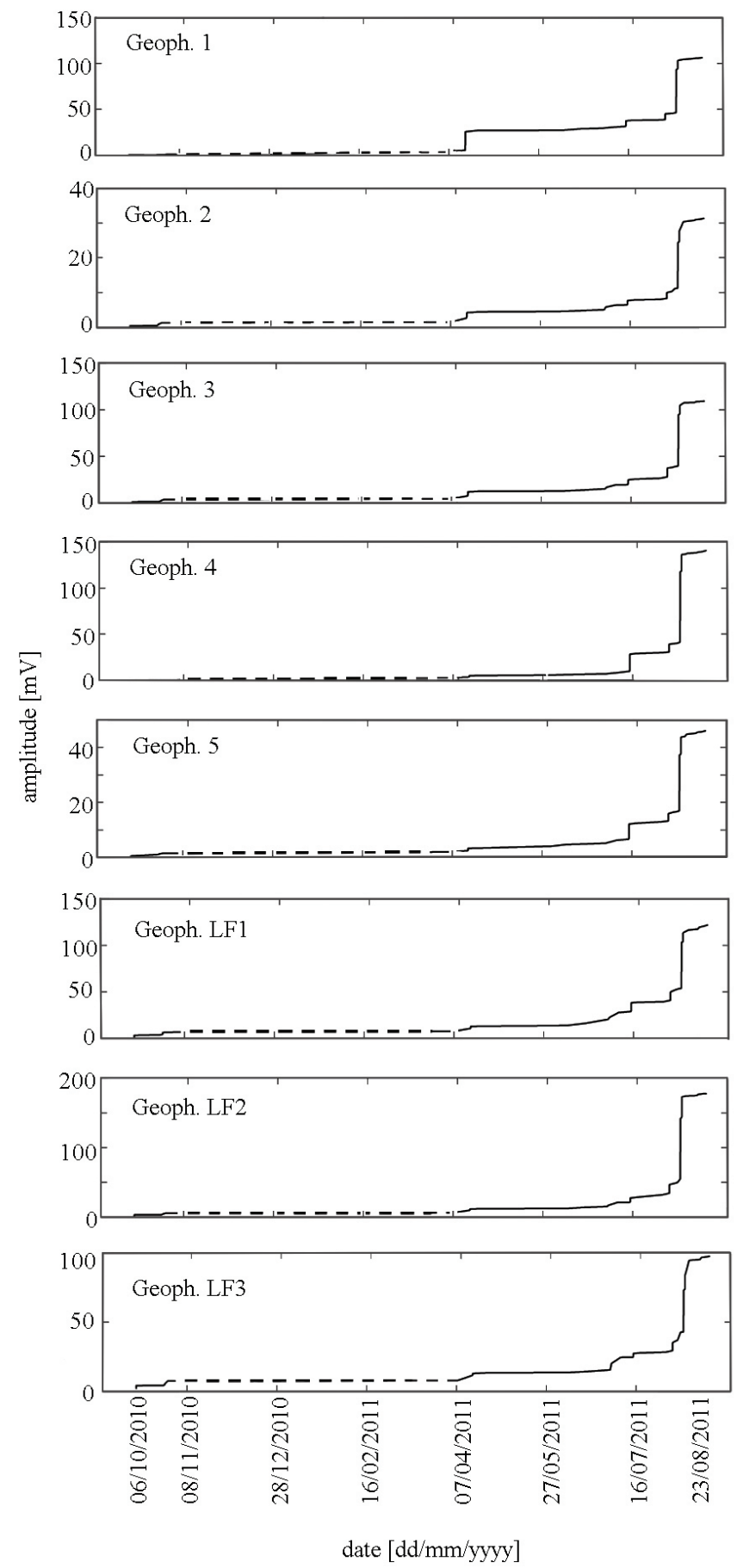

b)
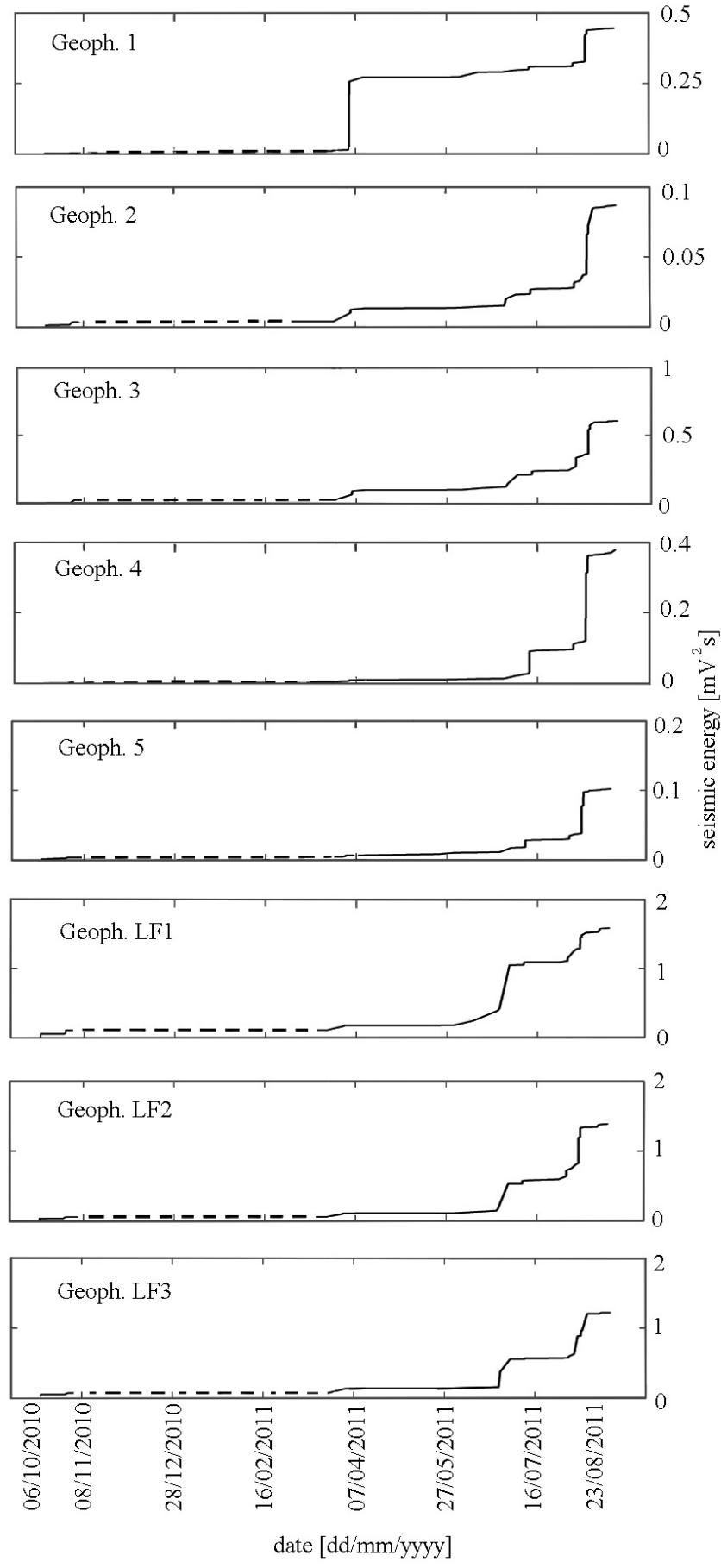

Fig. 11. Cumulative distribution of the (a) maximum amplitude and (b) seismic energy of the 162 multiple events recorded by each geophone. The dashed line represent the no-data period.

The most important concentration of MS activity (Fig. 12) occurs for rapid and intense lowering of air temperature during both cold and warm seasons as already reported in Amitrano et al. (2010). Minor concentrations of MS events can also be observed during the summer months when air temperature locally rises above $0{ }^{\circ} \mathrm{C}$. As already described in Sects. 4.1 and 4.2, these latter events show different spectral characteristics and can, thus, be reasonably ascribed to different kinematics of rock-mass deformation. In this sense, recent field observations on the Hörnligrat (Hasler et al., 


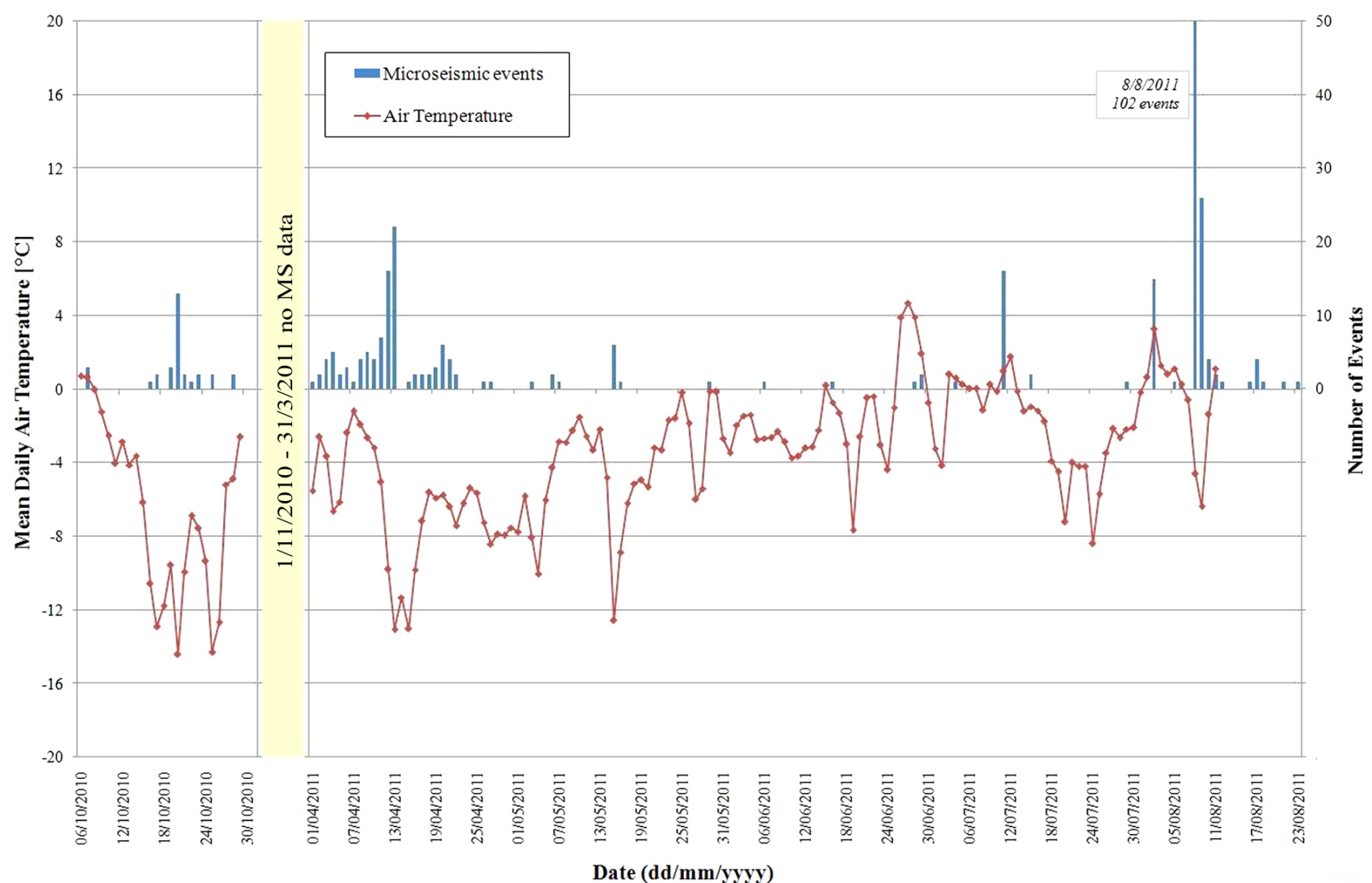

Fig. 12. Correlation between MS activity and temperature variations: continuous dot line represents the mean daily air temperature recorded close to the J. A. Carrel hut, on the North-West side of the ridge; histogram represents daily number of events.

2012), that is the North-Eastern ridge of Matterhorn, show that: (i) cleft movements during the cold season are caused by thermo-mechanical forcing and are reinforced by cryogenic processes during the freezing period, while, (ii) in summer the principal movements originate from hydro-thermally induced strength reduction (increase water pressure) in rock fractures containing perennial ice. These considerations allow us to hypothesize that the air temperature anomaly of April 2011 (Fig. 13) might have played a role in the high concentration of MS events registered in this month.

\section{Conclusions and further developments}

In high mountain areas, the formation and propagation of cracks in rock masses, which can eventually lead to rockfalls, can be influenced by particular climatic conditions. Since rock-falls are usually accompanied by the release of stored elastic energy that can be detected by a suitable array of MS transducers, an increase of MS activity and the monitoring of temperatures could contribute to identifying potentially unstable areas. In the present paper, the abovementioned aspects have been investigated analysing the MS data registered during the period October 2010 - August 2011 by a geophone network, jointly with thermometric data recorded by thermometric sensor, installed on the Matterhorn (Italian Alps) in the surroundings of the J. A. Carrel hut.

The analysis of a set of hammer strokes, which were used to test the proper functioning of the geophone monitoring system, has evidence of a good correlation between the characteristics of the recorded signals (in time and frequency domain) and the distance between the signal sources and the sensors, in spite of the high fracturation degree of the rock mass: this fact could be interpreted as due to debris and ice filled fractures.

The data collected by the MS monitoring system during the first year of recording are not continuous, as some technical problems caused an interruption of the recording between November 2010 and March 2011. The available data have been preliminarily analysed through a classification and a characterisation in the time and frequency domains.

The recorded events have been divided into two main classes: the first class is characterised by single events, while the second by multiple events (i.e., more than one event is present in the same recording). 


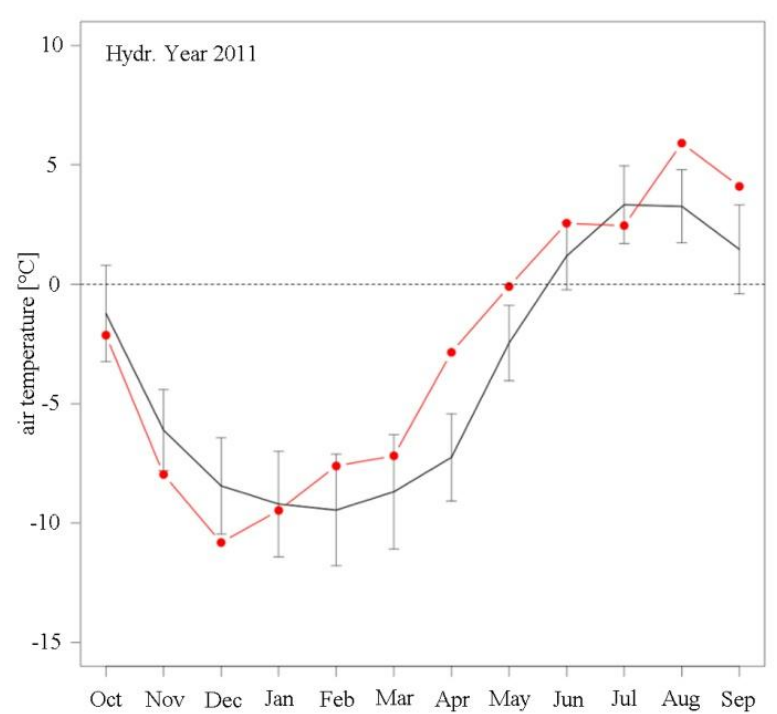

Fig. 13. Air temperature anomalies at $3100 \mathrm{~m}$ a.s.l. in the Matterhorn area (Italian side) during the hydrological year 2011. Comparison between the monthly mean air temperature recorded from October 2010 to September 2011 (red line) and the long-term climatic means of the period 1961-1990 (black line). The vertical lines represent the standard deviation for each month.

The analysis of the amplitude and of the seismic energy characterising the traces recorded by each geophone showed that many of the single events could be ascribed to superficial sources, while most of the sources of the multiple events appear to be located in the South-Western side of the network. Moreover, the analysis of the frequency content of the recorded events led to observe that many of the multiple events are characterised by low frequencies. This latter occurrence has been tentatively explained, on the basis of literature data, subdividing the multiple events in two categories: the first category includes MS events that could have been caused by a short succession of cracks, while the second one includes MS events which could have been produced by a sequence of falling blocks. This interpretation is in agreement also with the seasonal distribution of multiple and single events.

The comparison of the MS data with air temperature records has evidenced a temporal concentration of the MS activity when the temperatures rapidly fall. The same was observed for winter months (from November 2007 to April 2008) during a previous period of monitoring of the area (Amitrano et al., 2010). Minor concentrations of the MS activity can also be observed during the summer months when air temperature recorded by the local sensor temporarily raised above $0^{\circ} \mathrm{C}$. The positive air temperature anomaly of April 2011 might also have played a role in the high concentration of MS events registered in this month.

At the present time, the research is still in progress and the recording and interpretation of events and temperatures is planned for a longer period to better understand the relation between climate, MS data and rock slope instability. To this aim, a location of the MS sources will be performed to gather indications on the eventual presence of weakness zones in the investigated area in correspondence to spatial concentrations of located hypocentres. A precise location of MS sources will require an accurate knowledge of the propagation velocity model, which will be computed using the hammer stroke dataset.

Acknowledgements. The described activity has been developed in the frame of the Alcotra (Alpes Latines COopération TRAnsfrontalière) 2007-2013 project no. 56 MASSA (Medium And Small Size rock-fall hazard Assessment). The authors wish to thank the Regione Autonoma Valle d'Aosta (Dipartimento Difesa del Suolo e Risorse Idriche - Servizio Geologico), for the logistic and the financial support; Massimo Signori and Delfino Bani of the Solgeo S.r.l., who assembled and installed the monitoring network; Lucio Trucco and the Società delle Guide del Cervino, for the assistance during all the field work phases; Franco Godone and Marco Baldo of the CNR IRPI Torino, for the technical assistance during the topographic survey and topographic data elaboration. This work would not have been achieved without the precious suggestions of Gianni Mortara, senior researcher of the CNR IRPI Torino.

Edited by: M. Arai

Reviewed by: L. Paro and N. A. Smirnova

\section{References}

Amitrano, D., Grasso, J. R., and Senfaute, G.: Seismic precursory patterns before a cliff collapse and critical point phenomena, Geophys. Res. Lett., 32, L08314, doi:10.1029/2004GL022270, 2005 .

Amitrano, D., Arattano, M., Chiarle, M., Mortara, G., Occhiena, C., Pirulli, M., and Scavia, C.: Microseismic activity analysis for the study of the rupture mechanisms in unstable rock masses, Nat. Hazards Earth Syst. Sci., 10, 831-841, doi:10.5194/nhess10-831-2010, 2010.

Arosio, D., Longoni, L., Papini, M., Scaioni, M., Zanzi, L., and Alba, M.: Towards rockfall forecasting through observing deformations and listening to microseismic emissions, Nat. Hazards Earth Syst. Sci., 9, 1119-1131, doi:10.5194/nhess-9-1119-2009, 2009.

Deparis, J., Jongmans, D., Cotton F., Baillet L., Thouvenot F., and Hantz D.: Analysis of rock-fall and rock-fall avalanche seismograms in the French Alps, B. Seism. Soc. Am., 98, 1781-1796, 2008.

Dixon, N., Hill, R., and Kavanagh, J.: Acoustic emission monitoring of slope instability: development of an active waveguide system, Geotech. Eng., 156, 83-95, 2003.

Gruber, S., Hoelzle, M., and Haeberly, W.: Permafrost thaw and destabilization of Alpine rock walls in the hot summer of 2003, Geophys. Res. Lett., 31, L13504, doi:10.1029/2004GL020051, 2004. 
Hasler, A., Gruber S., and Beutel, J.: Kinematics of steep bedrock permafrost, J. Geophys. Res., 117, F01016, doi:10.1029/2011JF001981, 2012.

Kolesnikov, Yu. I., Nemirovich-Danchenko, M. M., Goldin, S. V., and Seleznev, V. S.: Slope stability monitoring from microseismic field using polarization methodology, Nat. Hazards Earth Syst. Sci., 3, 515-521, doi:10.5194/nhess-3-515-2003, 2003.

Levy, C., Jongmans, D., and Baillet, L.: Analysis of seismic signals recorded on a prone-to-fall rock column (Vercor Massif, French Alps), Geophys. J. Int., 186, 296-310, doi:10.1111/j.1365246X.2011.05046.x, 2011.

Lockner, D. A.: The role of acoustic emission in the study of rock fracture, Int. J. Rock Mech. Min. Sci. Geomech. Abstr., 30, 883899, 1993.

Obert, L. and Duvall, W. I.: Use of subaudibile noises for the prediction of rock bursts, Part II, RI 3654, USBM, 1942.

Occhiena, C.: Microseismic activity in rock masses: identification, analysis and interpretation, Ph.D. Thesis, Politecnico di Torino, Italy, 2011.
Senfaute, G., Merrien-Soukatchoff, V., Morel, J., and Gourry, J. C.: Microseismic monitoring applied to prediction of chalck cliffs collapse and contribution of numerical modeling, Proceedings of International Conference on fast Slope Movements, 11-13 May 2003, edited by: Picarelli, L., Naples, Italy, 463-468, 2003.

Senfaute, G., Duperret, A., and Lawrence, J. A.: Micro-seismic precursory cracks prior to rock-fall on coastal chalk cliffs: a case study at Mesnil-Val, Normandie, NW France, Nat. Hazards Earth Syst. Sci., 9, 1625-1641, doi:10.5194/nhess-9-1625-2009, 2009.

Shiotani, T.: Evaluation of long-term stability for rock slope by means of acoustic emission technique, NDT \& International, 39, 217-228, 2006.

Signori, M. and Bani, D.: Cervino - Capanna Carrel. Impianto di monitoraggio per emissioni acustiche, Solgeo s.r.l., Internal Report, Rel. V10P0803, 2010.

Spillmann, T., Maurer, H., Green, A. G., Heincke, B., Willenberg, H., and Husen, S: Microseismic investigation of an unstable mountain slope in the Swiss Alps, J. Geophys. Res., 112, B07301, doi:10.1029/2006JB004723, 2007. 